\title{
Persistence of severe iodine-deficiency disorders despite universal salt iodization in an iodine-deficient area in northern India
}

\author{
Subhash Yadav ${ }^{1}$, Sushil Kumar Gupta ${ }^{1}$, Madan M Godbole ${ }^{1, *}$, Manoj Jain ${ }^{2}$, \\ Uttam Singh ${ }^{3}$, Praveen V Pavithran ${ }^{1}$, Raman Boddula ${ }^{1}$, Anand Mishra ${ }^{4}$, Ashutosh \\ Shrivastava ${ }^{1}$, Ashwani Tandon ${ }^{1}$, Manish Ora ${ }^{5}$, Amit Chowhan $^{2}$, Manoj Shukla ${ }^{1}$, \\ Narendra Yadav ${ }^{1}$, Satish Babu ${ }^{4}$, Manoj Dubey ${ }^{1}$ and Pradeep K Awasthi ${ }^{1}$ \\ 'Department of Endocrinology, Sanjay Gandhi Postgraduate Institute of Medical Sciences, Lucknow 226014, \\ India: ${ }^{2}$ Department of Pathology, Sanjay Gandhi Postgraduate Institute of Medical Sciences, Lucknow, India: \\ ${ }^{3}$ Department of Biostatistics, Sanjay Gandhi Postgraduate Institute of Medical Sciences, Lucknow, India: \\ ${ }^{4}$ Department of Endocrine Surgery, Sanjay Gandhi Postgraduate Institute of Medical Sciences, Lucknow, India: \\ ${ }^{5}$ Department of Nuclear Medicine, Sanjay Gandhi Postgraduate Institute of Medical Sciences, Lucknow, India
}

Submitted 28 May 2008: Accepted 29 April 2009: First published online 11 June 2009

\begin{abstract}
Objective: The aim of the present study was to determine the impact of universal salt iodization (USI) on the prevalence of iodine deficiency in the population of an area previously known to have severe iodine deficiency in India.

Design: In a cross-sectional survey, a total of 2860 subjects residing in fifty-three villages of four sub-districts of Gonda District were examined for goitre and urinary iodine concentration. Free thyroxine and thyroid-stimulating hormone levels were also measured. Salt samples from households were collected for estimation of iodine content.

Results: A reduction in goitre prevalence was observed from $69 \%$ reported in 1982 to $27.7 \%$ assessed in 2007 . However, $34 \%$ of villages still had very high endemicity of goitre (goitre prevalence $>30 \%$ ). Twenty-three per cent of households consumed a negligible amount $(<5 \mathrm{ppm})$ and $56 \%$ of households consumed an insufficient amount (5-15 ppm) of iodine from salt.

Conclusions: Although there was an overall improvement in iodine nutrition as revealed by decreased goitre prevalence and increased median urinary iodine levels, there were several pockets of severe deficiency that require a more targeted approach. Poor coverage, the use of unpackaged crystal salt with inadequate iodine and the washing of salt before use by $90 \%$ of rural households are the major causes of persisting iodine-deficiency disorders. This demonstrates lapses in USI implementation, lack of monitoring and the need to identify hot spots. We advocate strengthening the USI programme with a mass education component, the supply of adequately iodized salt and the implementation of complementary strategies for vulnerable groups, particularly neonates and lactating mothers.
\end{abstract}

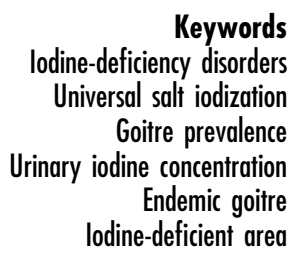

Eighty-four per cent of the 130 countries affected by iodine-deficiency disorders (IDD) have either national legislation or a draft on salt iodization in place ${ }^{(1)}$. Worldwide, the sustainability of IDD control programmes has become a major focus. In several countries in which IDD was eliminated by universal salt iodization (USI), control programmes faltered, IDD recurred ${ }^{(2,3)}$ and new cases of cretinism have also appeared ${ }^{(4,5)}$.

On recommendations of the Central Council of Health in 1984, the Government of India took a policy decision with the goal of 'universal iodization of salt'. Despite remarkable progress in the control of IDD, it remains a significant public health problem in India $^{(6-8)}$. It has been estimated that 200 million people in India are exposed to the risk of iodine deficiency and more than 71 million suffer from goitre and other IDD ${ }^{(9)}$. The central notification restricting the sale of non-iodized salt was relaxed in late 2000 by removing the punitive clause. Although the restriction on the sale of noniodized salt was re-imposed in November 2005, it did not take effect until May $2006^{(10)}$. Assessing the severity of IDD and monitoring the progress of salt iodization programmes remains the cornerstone of any control strategy.

The National Family Health Survey-III revealed that $51 \%$ of households were using adequately iodized salt 
(iodine content $\geq 15 \mathrm{ppm}$ ) and approximately $25 \%$ of the population was using non-iodized salt ${ }^{(11)}$. The benefits of USI have often accrued to the urban population due to better coverage and availability of packaged, fine iodized salt ${ }^{(5,11)}$. This is often the case with big metropolises situated in mild iodine-deficient areas. USI monitoring teams often overlook the poor coverage of the programme in severely affected rural communities. Seventy-seven per cent of households in large cities, $72 \%$ in small cities and towns and only $41 \%$ in rural areas use salt with the recommended level of $\geq 15 \mathrm{ppm}$ iodine ${ }^{(11)}$. It is reported that though globally iodine nutrition has greatly improved, $20 \%$ to $30 \%$ of pregnancies and thus newborns still do not fully benefit from the use of iodized salt ${ }^{(2)}$.

The principal indicators of an effective programme are the household availability of iodine through edible salt and the median urinary iodine concentration (UIC) in a population, because it is highly sensitive to recent changes in iodine intake ${ }^{(12)}$. Goitre rate that reflects thyroid size is a poor secondary indicator, not only because it indicates just the history of iodine malnutrition but also because of subjective discrepancies that may creep in among the evaluators ${ }^{(12)}$. Most often, however, it is the only indicator that is assessed in endemic areas due to constraints on financial and trained human resources. Moreover, persisting goitre in the first few years of childhood often takes a long time to regress ${ }^{(13,14)}$.

The present study was undertaken to objectively assess the status of the IDD control programme in Gonda District, located in the sub-Himalayan region of northern India, which had a reported goitre prevalence of $69 \%$ and high neonatal chemical hypothyroidism in the year $1982^{(15,16)}$.

\section{Material and methods}

\section{Subjects}

We carried out the cross-sectional field survey in Gonda District of Uttar Pradesh province, situated in the subHimalayan region approximately $120 \mathrm{~km}$ north-east of Lucknow, the provincial capital. The study was carried out from 28 April 2007 to 14 July 2007. The most recent census data in 2001 showed that the district has four subdistricts, 1815 villages and a total population of $2 \cdot 7$ million.

The sample size was calculated to be 2875 subjects on the basis of an assumed goitre prevalence of 50\%, 95\% confidence interval, a design effect of $1 \cdot 5$, a relative precision of $10 \%$ and a non-response rate of $3 \%$. We randomly selected fifty-three villages and ten houses in each village.

All subjects underwent evaluation of goitre size by palpation. Goitre was graded as per the WHO classification (grade 0 , no goitre; grade 1, palpable but not visible; grade 2, clearly visible with the neck in normal position $)^{(1)}$. Before undertaking the goitre prevalence survey, the members of the clinical teams checked their techniques of grading of goitre for inter-observer variation. Three teams of two clinical thyroidologists each carried out the goitre grading. Initially, unacceptably high variations in goitre grading were observed among the three teams deployed for the field survey. To resolve the problem, all clinicians in the three teams examined twentyfive children (aged 6-14 years) in a primary school and recorded the thyroid grading in a blinded fashion. A consensus was arrived at, ensuring uniform goitre grading. In the situation of variation in goitre grade between two members in a given subject, the immediate lower goitre grade was assigned. Since the area that was surveyed had high prevalence of cretinism a few decades ago, the prevalence of deaf-mutism, spastic diplegia, squint and dwarfism in subjects older than 20 years was recorded. To assess salt purchasing habits, its household processing, storage and use, a 'knowledge, attitude and practice' (KAP) questionnaire was utilized and administered to the woman of each house. Informed consent was obtained from all study subjects. The project was approved by the Institute's Ethics Committee.

\section{Biochemical analysis}

Spot urine $(10-15 \mathrm{ml})$ was collected from every second subject and preserved in a plastic bottle containing a few drops of toluene. A sample of salt (approx $100 \mathrm{~g}$ ) was collected in a self-sealing plastic pouch from $70 \%$ of surveyed households. A blood sample $(10 \mathrm{ml})$ was drawn from every tenth individual; serum separated after centrifugation $(500 \mathrm{~g})$ at room temperature was preserved on ice. Serum samples were transported to the laboratory on ice and stored at $-20^{\circ} \mathrm{C}$ until the time of assay.

UIC was measured using a kit (Bioclone Australia Pty Limited, Sydney, Australia) based on the Sandell-Koltoff reaction $^{(17)}$. The sensitivity of the method was $10 \mu \mathrm{g} / \mathrm{l}$, with a range of $10-400 \mu \mathrm{g} / \mathrm{l}$. The intra- and inter-assay $\mathrm{CV}$ were $6.5 \%$ and $10.5 \%$, respectively, for iodine content of medium range $(130-200 \mu \mathrm{g} / 1)$.

Iodine content of salt was estimated by iodometric titration $^{(18)}$ and is expressed in parts per million. Serum free thyroxine $\left(\mathrm{FT}_{4}\right)$ and thyroid-stimulating hormone (TSH) were measured by radioimmunoassay and immunoradiometric assay, respectively, using commercially available kits (Diagnostic Products Corporation, New York, NY, USA).

\section{Statistical analysis}

Statistical analysis of data was carried out using the SPSS statistical software package version $14 \cdot 0$ (SPSS Inc., Chicago, IL, USA). Goitre prevalence is presented as percentage of the study population. The iodine status of subjects was determined using the recommended WHO/ UNICEF/International Council for the Control of Iodine Deficiency Disorders criteria ${ }^{(1)}$. Salt samples were categorized according to iodine content. Results are expressed as medians for UIC and salt iodine content, means 
Table 1 Goitre prevalence in the study population: subjects $(n$ 2860) residing in fifty-three villages of Gonda District, northern India

\begin{tabular}{|c|c|c|c|c|c|c|}
\hline \multirow[b]{2}{*}{ Age group } & \multicolumn{2}{|c|}{ Males } & \multicolumn{2}{|c|}{ Females } & \multicolumn{2}{|c|}{ Combined } \\
\hline & $\%$ & $n / N^{*}$ & $\%$ & $n / N$ & $\%$ & $n / N$ \\
\hline $1-17$ years & $24 \cdot 9$ & $205 / 823$ & $29 \cdot 1$ & $206 / 708$ & $26 \cdot 8$ & $411 / 1531$ \\
\hline Schoolchildren, 6-12 yearst & $29 \cdot 4$ & $123 / 419$ & $32 \cdot 8$ & $125 / 381$ & $31 \cdot 0$ & $248 / 800$ \\
\hline $18-40$ years & $16 \cdot 6$ & $51 / 308$ & $36 \cdot 7$ & $168 / 458$ & $28 \cdot 6$ & $219 / 766$ \\
\hline$>40$ years & $16 \cdot 9$ & $48 / 284$ & $40 \cdot 5$ & $113 / 279$ & $28 \cdot 6$ & $161 / 563$ \\
\hline All except subgroup & $21 \cdot 5$ & $304 / 1415$ & 33.7 & $487 / 1445$ & $27 \cdot 7$ & $791 / 2860$ \\
\hline
\end{tabular}

${ }^{*}$ Number of subjects with goitre/total number of subjects examined.

tSubgroup within age group 1-17 years.

and standard deviations for serum $\mathrm{FT}_{4}$ and TSH. Categorical variables were compared using the $\chi^{2}$ test. $P$ values less than 0.05 were considered statistically significant.

\section{Results}

We surveyed 2860 subjects (1415 males, 49.5\%; 1445 females, $50.5 \%$ ) in fifty-three geographically well distributed villages. As shown in Table 1 , the goitre prevalence in the study population was $27 \cdot 7 \%$ (95\% CI, 26•0, 29.3\%). Goitre prevalence was significantly higher $(P<0 \cdot 001)$ among females $(33 \cdot 7 \%)$ compared with males $(21 \cdot 5 \%)$. Goitre prevalence in the youngest age group of females (1-17 years) was $29 \cdot 1 \%$, increasing to $40 \cdot 5 \%$ in the oldest age group ( $>40$ years, $P<0 \cdot 001$ ). There was a significant difference observed in the goitre prevalence among males of different age groups $(P=0 \cdot 001)$. Children in age the group of 6-12 years showed a goitre prevalence of $31 \cdot 0 \%$. Strikingly, study subjects in $34 \%$ of villages still suffered from severe iodine deficiency (goitre rate of $>30 \%$ ).

Table 2 summarizes UIC levels. Severe iodine deficiency (UIC $<20 \mu \mathrm{g} /$ l) was present in $8.0 \%$ of the study population while moderate $(20-49 \mu \mathrm{g} / \mathrm{l})$ and mild deficiency $(50-99 \mu \mathrm{g} / \mathrm{l})$ was present in $12 \cdot 5 \%$ and $27 \cdot 3 \%$ of the population, respectively. The median UIC was $100 \mu \mathrm{g} / \mathrm{l}(0.79 \mu \mathrm{mol} / \mathrm{l})$ with range of $5 \cdot 0$ to $560 \mu \mathrm{g} / \mathrm{l}$.

Table 3 shows median and range of UIC and salt iodine content, as well as mean and standard deviation of circulating $\mathrm{FT}_{4}$ and TSH levels. The median iodine content of household salt of $6.3 \mathrm{ppm}$ indicates an ineffective USI programme in several pockets of the district. Table 4 shows that only $21 \%$ of households were consuming adequately iodized salt ( $\geq 15 \mathrm{ppm}$ ). Thus $79 \%$ of households were still consuming salt with either inadequate or almost negligible iodine content.

The wide range of UIC values prompted us to undertake a detailed village-wise analysis of goitre prevalence, UIC and salt iodine contents. The results indicated a significant presence of goitre and inadequate iodine intake in many villages (Table 5).

The results of the KAP questionnaire revealed the vital information that more than $90 \%$ of subjects purchased locally available salt with average crystal size range of
Table 2 Urinary iodine concentration (UIC) in the study population: subjects $(n 1236)$ residing in fifty-three villages of Gonda District, northern India

\begin{tabular}{lrr}
\hline UIC $(\mu \mathrm{g} / \mathrm{l})$ & $\%$ & $n$ \\
\hline$<20$ & $8 \cdot 0$ & 99 \\
$20-49$ & $12 \cdot 5$ & 154 \\
$50-99$ & $27 \cdot 3$ & 337 \\
$\geq 100$ & $52 \cdot 2$ & 646 \\
\hline
\end{tabular}

UIC in $\mu \mathrm{mol} / \mathrm{I}=\mathrm{UIC}$ in $\mu \mathrm{g} / \mathrm{l} \times 0.0079$.

Table 3 Median urinary iodine concentration (UIC) and salt iodine content, and mean free thyroxine $\left(\mathrm{FT}_{4}\right)$ and thyroid-stimulating hormone (TSH) levels in the study population: subjects residing in fifty-three villages of Gonda District, northern India

\begin{tabular}{|c|c|c|c|c|}
\hline Parameter & Median & Mean & SD & Range \\
\hline & $100 \cdot 0$ & & & $5 \cdot 0-560$ \\
\hline Salt iodine (ppm), $n_{\text {households }} 338$ & $6 \cdot 3$ & & & $1 \cdot 10$ \\
\hline $\mathrm{FT}_{4}{ }^{*}(\mathrm{ng} / \mathrm{dl}), n 293$ & & $1 \cdot 1$ & 0.5 & $0 \cdot 7-3 \cdot 5$ \\
\hline $\mathrm{TSH}+(\mu \mathrm{U} / \mathrm{ml}), n 290$ & & $3 \cdot 1$ & $5 \cdot 7$ & $0 \cdot 5-60$ \\
\hline
\end{tabular}

*Normal range: $\mathrm{FT}_{4}=0 \cdot 7-2 \cdot 0 \mathrm{ng} / \mathrm{dl}$.

tNormal range: $\mathrm{TSH}=0 \cdot 5-5 \cdot 0 \mu \mathrm{U} / \mathrm{ml}$.

Table 4 Household ( $n$ 338) salt iodine content in fifty-three villages of Gonda District, northern India

\begin{tabular}{lc}
\hline Salt iodine $(\mathrm{ppm})$ & \% of households \\
\hline$<5$ & $23 \cdot 4$ \\
$5-14 \cdot 99$ & $55 \cdot 6$ \\
$15-30$ & $12 \cdot 4$ \\
$>30$ & $8 \cdot 6$ \\
\hline
\end{tabular}

Table 5 Village-wise analysis of analysis of goitre prevalence, urinary iodine concentration (UIC) and salt iodine content in fiftythree villages of Gonda District, northern India

\begin{tabular}{lc}
\hline Indicator & $\begin{array}{c}\% \text { of } \\
\text { villages }\end{array}$ \\
\hline Goitre prevalence & 85 \\
$>5 \%$ & 34 \\
$>30 \%$ & \\
Median UIC & 34 \\
$<100 \mu \mathrm{g} / \mathrm{l}$ & 10 \\
$<50 \mu \mathrm{g} / \mathrm{l}$ & 21 \\
Proportion consuming adequate iodized salt & \\
$\quad(\geq 15 \mathrm{ppm})$ & \\
\hline
\end{tabular}


25-50 $\mathrm{mm}$ (1-2 in) from roadside vendors and washed their salt with water to remove dust particles before pulverization and use. Women from the majority of households confirmed that salt forms hard lumps on prolonged storage in powdered form under the humid conditions prevalent in this area for most of the year.

Associated subclinical hypothyroidism $(\mathrm{TSH}>5 \cdot 0 \mu \mathrm{U} / \mathrm{ml}$ and $\mathrm{FT}_{4}<0.7 \mathrm{ng} / \mathrm{dl}$ ) was present in $10 \%$ of the study population (data not shown). Although we recorded eight children with one or more cretinoid features, we did not record any cretin in the age group of $>20$ years (data not shown).

\section{Discussion}

The study shows that the overall goitre prevalence rate in Gonda District has undergone a significant decrease over the past two decades (last survey done in the year 1982) ${ }^{(15,16)}$. The outcome indicators such as UIC, TSH and $\mathrm{FT}_{4}$ levels point to a satisfactory implementation of the USI programme in this district. However, the moderate degree of goitre prevalence and the low iodine content of salt depict a less than ideal implementation of USI in certain pockets of the district.

The persistence of higher goitre prevalence in females seen in the present study has also been reported in other endemic areas ${ }^{(19-21)}$. The documented failure to meet females' requirements in a crucial period of growth, pregnancy and lactation also holds true for iodine nutrition ${ }^{(11)}$. This may be further accentuated by the higher circulating thiocyanate levels reported earlier in females from the same area $^{(22)}$. The goitre prevalence and UIC data in schoolchildren are in agreement with earlier reports, suggesting only partial success of the programme $e^{(8,23,24)}$.

Village-wise analysis of goitre prevalence, UIC and salt iodine content further indicates that satisfactory iodine nutrition is achieved in only one-third of the villages (Table 5). Strikingly, in $85 \%$ of villages, the goitre prevalence rate is well above the internationally accepted norm. The situation in these groups of villages is more complex and heterogeneous. Half of the villages in this group had a much higher goitre prevalence of $49 \%$ despite median UIC levels being satisfactory. In contrast, subjects from an equal number of villages had a much lower goitre prevalence of $29 \%$, albeit higher than the internationally acceptable norm, despite UIC levels showing unsatisfactory iodine nutrition. This heterogeneous picture could in part be explained by: (i) a possible contribution of thiocyanate and other goitrogens as reported previously from the same area ${ }^{(22)}$; and (ii) single point analysis may not reflect the USI failure at earlier times ${ }^{(13)}$.

The non-significant correlation between goitre rate and urinary iodine (data not shown) indicates it as a poor indicator of success of USI because it reflects a population's history of iodine nutrition and not its present status. The results are in agreement with earlier studies showing that goitre rates may not become normal for months or years following implementation of USI ${ }^{(25,26)}$. A number of recent epidemiological surveys have shown that, in spite of satisfactory urinary iodine levels, goitre rates are still on the high side ${ }^{(7,8,13)}$.

However, poor availability of iodine through edible salt in rural areas (only $21 \%$ of households received adequate iodized salt compared with $41 \%$ according to the NFHSIII survey) remains the main factor accounting for IDD in Gonda District. The use of unpacked crystalline salt and its washing with water before use is a standard culinary practice in the majority of households and is the major cause of persisting severe iodine deficiency in many villages. This salt is available only in bigger crystal size and powdered salt displays a tendency for lump formation due to high $\mathrm{Ca}$ content. A large population still suffers from moderate to severe iodine deficiency due to insufficient iodine consumption at household level for the following reasons: (i) the practice of washing salt before use; (ii) inability to afford adequately iodized packaged salt for financial reasons; and (iii) lack of health awareness.

Identification of hot spots of severe persisting IDD calls for constant monitoring and evaluation of IDD control in USI implementation programmes. This also indicates a strong need to formulate alternative strategies in specific areas. Similar hot spots might be present in other underdeveloped countries having USI programmes. Emphasis should be given to pregnant women, lactating mothers and children up to 3 years of age to evaluate the impact of iodization. This becomes particularly important in Indian communities, as the only source of food up to 1 year in infants is mother's milk. Adequate iodine should be ensured to sustain brain development during this period.

USI seems to have worked to prevent further cretins being born; however, it has not helped to reduce goitre prevalence rates to a desirable level of $<5 \%$ among most susceptible populations/villages. The impact of lapses in implementation of USI on the learning potential of children from the most affected villages needs to be assessed.

The first reason for the partial failure of USI seems to be inability to teach the rural masses, to adapt to the situation wherein washing of the iodized crystal salt should be discouraged. The matching health education essential to achieve results is grossly lacking. The USI programme in Uttar Pradesh should have a massive education component built in for it to succeed. Second, it was found that the districts receiving iodized salt by road had a higher number of salt samples with negligible iodine content as compared with the districts receiving iodized salt by rail transport. The inspectors of the salt department vigilantly monitor the quality of salt transported by railways before it is loaded to the train. However, no monitoring of salt quality is done for transportation of salt by road. The issue assumes importance in view of startling figures from 
the UNICEF regional office in Lucknow that, since the freight hike by railways, approximately $30 \%$ of salt reaching Uttar Pradesh is coming through road transport $^{(27)}$. Finally, other state governments have successfully adopted the supply of smaller crystalline salt with less Ca content and better iodine retention ${ }^{(28)}$. The Uttar Pradesh Government as well as wholesale traders need to follow this to fulfil their social responsibility towards the rural population.

The results suggest the need for formulating a mission approach for the state of Uttar Pradesh with two clear components: (i) action on the demand side to make communities aware of the need to use adequately iodized salt; and (ii) action on the supply side to ensure the distribution and sale of adequately iodized salt. The state government's mission should be to seek cooperation of the salt commissioner, traders, transporters, the UNICEF regional office and independent monitoring agencies to formulate strategies for time-bound implementation of USI.

\section{Acknowledgements}

Sources of funding: The study was funded by financial support from the Council for Science and Technology, Government of Uttar Pradesh, India to M.M.G. (no. CST/ SERPD/D-10) and an intramural grant of the Sanjay Gandhi Postgraduate Institute of Medical Sciences, Lucknow to S.Y. (no. PGI/DIR/RC/588/2005). Conflict of interest declaration: None of the authors had a conflict of interest. Authors' contributions: S.Y. designed the study, collected and analysed the data, and wrote the manuscript. S.K.G. designed the study, collected and analysed the data. M.M.G. designed the study, collected and analysed the data, and wrote the manuscript. M.J. performed the clinical evaluation of IDD. U.S. conducted the sample size design of the study and analysed the data. P.V.P performed the clinical evaluation of IDD. R.B. performed the clinical evaluation of IDD. A.M. performed the clinical evaluation of IDD. A.S. undertook specimen collection. A.T. performed the clinical evaluation of IDD. M.O. performed the clinical evaluation of IDD. A.C. performed the IDD clinical evaluation. M.S. performed the hormone analysis. N.Y. performed the salt analysis. S.B. performed the urine analysis. M.D. performed the hormone analysis. P.K.A. performed the hormone analysis. Acknowledgments: We gratefully acknowledge officers and staff of Indian Telecom Industry (ITI), Mankapur and the District Hospital Gonda for their help in the field. The cooperation and willingness of the subjects of study population is gratefully acknowledged.

\section{References}

1. de Benoist B, Andersson M, Egli I, Takkouche B \& Allen H (editors) (2004) Iodine Status Worldwide. WHO Global
Database on Iodine Deficiency, pp. 1-3. Geneva: WHO; available at http://whqlibdoc.who.int/publications/2004/ 9241592001.pdf

2. Maberly GF, Haxton DP \& van der Haar F (2003) Iodine deficiency: consequences and progress toward elimination. Food Nutr Bull 24, 4 Suppl., S91-S98.

3. Anderson M, Takkouche B, Egli I, Allen HE \& de Benoist B (2005) Current global iodine status and progress over the last decade towards the elimination of iodine deficiency. Bull World Health Organ 83, 518-525.

4. Markou KB, Georgopoulos NA, Makri M et al. (2001) Iodine deficiency in Azerbaijan after the discontinuation of an iodine prophylaxis program: reassessment of iodine intake and goiter prevalence in schoolchildren. Thyroid $\mathbf{1 1}$, 1141-1146.

5. Cetin H, Kisioglu AN, Gursoy A, Bilaloglu E \& Ayata A (2006) Iodine deficiency and goitre prevalence in Turkey after mandatory iodization. J Endocrinol Invest 29, $714-718$.

6. Vir SC (2002) Current status of iodine deficiency disorders (IDD) and strategy for its control in India. Indian J Pediatr 69, 589-596.

7. Kapil U, Sharma TD, Singh P, Dwivedi SN \& Kaur S (2005) Thirty years of a ban on the sale of noniodized salt: impact on iodine nutrition in children in Himachal Pradesh, India. Food Nutr Bull 26, 255-258.

8. Sankar R, Moorthy D, Pandav CS, Tiwari JS \& Karmarkar MG (2006) Tracking progress towards sustainable elimination of iodine deficiency disorders in Bihar. Indian $J$ Pediatr 73, 799-802.

9. National Institute of Health and Family Welfare (2003) National Iodine Deficiency Disorders Control Program: National Health Program Series 5, p. 99. New Delhi: Department of Communication, National Institute of Health and Family Welfare.

10. Sankar R \& Pandav CS (2005) Ban on sale of non-iodized salt for human consumption: a step in the right direction. Natl Med J India 18, 169-171.

11. International Institute for Population Sciences \& Macro International (2007) National Family Health Survey (NFHS3), 2005-06: India. vol. I. Mumbai: IIPS; available at http:// www.nfhsindia.org/volume_1.html

12. World Health Organization (2001) Assessment of Iodine Deficiency Disorders and Monitoring their Elimination: $A$ Guide for Programme Managers. WHO/NHD/01.1, 2nd ed. Geneva: WHO.

13. Zimmerman MB (2004) Assessing iodine status and monitoring progress of iodized salt program. J Nutr 134, 1673-1677.

14. Agheni-Lombardi F, Antonangeli L, Pinchera A et al. (1997) Effect of iodized salt on thyroid volume of children living in an area previously characterized by moderate iodine deficiency. J Clin Endocrinol Metab 82, 1136-1139.

15. Pandav CS \& Kochupillai N (1982) Endemic goitre in India: prevalence, etiology, attendant disabilities and control measures. Indian J Pediatr 49, 259-271.

16. Kochupillai N, Godbole MM, Pandav CS, Karmarkar MG \& Ahuja MM (1984) Neonatal thyroid status in iodine deficient environments of the sub-Himalayan region. Indian J Med Res 80, 293-299.

17. Ohashi T, Yamaki M, Pandav CS, Karmarkar MG \& Irie M (2000) Simple microplate method for determination of urinary iodine. Clin Chem 46, 529-536.

18. Tyabji R (1985) The Use of Iodated Salt in the Prevention of Iodine Deficiency Disorders: A Handbook of Monitoring and Quality Control. New York: UNICEF.

19. Sarkar S, Mohanty B \& Basu S (2007) Iodine deficiency in school going children of Pondicherry. Indian J Pediatr 74, 731-734.

20. Sen TK, Biswas AB, Chakrabarty I, Das DK, Ramakrishnan R, Manickam P \& Hutin Y (2006) Persistence of iodine 
deficiency in Gangetic flood-prone area, West Bengal, India. Asia Pac J Clin Nutr 15, 528-532.

21. Laway BA \& Zargar AH (2006) Iodine deficiency disorders in India. J Indian Med Assoc 104, 554-556.

22. Marwaha RK, Tandon N, Gupta N, Karak AK, Verma K \& Kochupillai N (2003) Residual goitre in the postiodization phase: iodine status, thiocyanate exposure and autoimmunity. Clin Endocrinol (Oxf) 59, 672-681.

23. Marwah RK, Tandon N, Karak AK, Gupta N, Verma K \& Kocupillai N (2000) Hashimoto's thyroiditis: countrywide screening of goitrous healthy young girls in postiodization phase in India. J Clin Endocrinol Metab 85, 3798-3802.

24. Kapil U, Sharma TD \& Singh P (2004) Iodine status and goitre prevalence after 40 years of salt iodisation in the Kangra District, India. Indian J Pediatr 74, 135-137.
25. Delange F, de Benoist B, Pretel E \& Dunn JT (2001) Iodine deficiency in the world: where do we stand at the turn of the century? Thyroid 11, 437-447.

26. Zimmermann MB, Moretti $\mathrm{D}$, Chaouki $\mathrm{N} \&$ Torresani $\mathrm{T}$ (2003) Introduction of iodized salt to severely iodinedeficient children does not provoke thyroid autoimmunity: a one-year prospective trial in northern Morocco. Thyroid 13, 199-203.

27. Kapil U, Tondon M, Pathak P \& Pradhan R (2001) Assessment of current status of salt iodization at the beneficiary level in selected districts of Uttar Pradesh, India. Indian Pediatr 38, 654-657.

28. Gerasimov C, Pandav CS, Benmiloud M, Delange FM \& Todd C (2002) The challenge ahead: iodized salt on every table for ever. Bull World Health Organ 80, 413-417. 